\title{
EDITORIAL
}

\section{POPULATION HEALTH AND AGING}

\author{
J.E. MORLEY, A.M. SANFORD
}

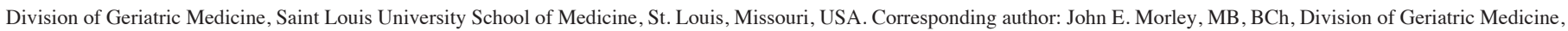
Saint Louis University School of Medicine, 1402 S. Grand Blvd., M238, St. Louis, MO 63104, Email: john.morley@health.slu.edu

Key words: Health and aging, population health, health outcomes.

The concept of "Population Health" is the understanding of the factors that modulate health outcomes of individuals living in a specific geographic area. This concept includes defining those distinguishing features amongst individuals residing in the same area that result in different outcomes. The data collected by the population health approach should lead to policy, regulation, and systems level change focusing on the economic, environmental, and social components that can lead to meaningful change in health outcomes for communities (1). The focus of population health is to move the focus from "health care" to "health." An appropriate implementation of population health should lead to a decrease in health care expenditure while increasing quality of life as well as life expectancy.

A great example of successful implementation of population health was the 1854 London cholera epidemic where there were 500 deaths in 10 days and which the epidemic was thwarted by removing the contaminated water pump handle. Other examples include the development of smallpox and other vaccines as well as discovery of the importance of hand washing in the health care setting. Professor McKeown pointed out that before the advent of antibiotics in the 1930s, the field of medicine had had a minimal effect on the large increase in life expectancy that had occurred in the previous century (2). The factors that were mainly responsible for the decrease in mortality in that era were purely economic, leading to enhanced environmental quality and increased food availability for the population.

\section{Atmospheric Pollution}

The Great Smog of London in 1952 resulted in 4,000 to 10,000 deaths occurring predominately in very young and older persons (3). Far greater numbers of people became ill during the 5 day-long stretch of polluted smog covering the city. The majority of deaths that occurred were due to hypoxia and respiratory diseases. Despite knowing the deleterious effects of air pollution on a population for many years, modern society continues to struggle with eliminating air contaminants. Pope et al (4) found that in cities in the United States of America, fine particulate air pollution (PM2.5 or greater) was associated with decreased life expectancy. Data collected in New York City, one of the top ten most polluted cities in the United
States, (5) found that $75 \%$ of deaths attributable to a >PM2.5 occurred in adults 65 and older. Similarly, an increase in deaths attributed to a defective ozone layer predominately took place in older persons. In one study, air pollution was responsible for over $60 \%$ of respiratory and cardiovascular hospitalizations in older persons. Interestingly, cockroaches play a part in air pollution in that they shed body parts and feces which act as allergenic air pollutants. There has been shown to be an increased mortality rate of persons living in housing with high cockroach infestation in the Bronx, New York. Additionally, similar effects of PM2.5 and greater have been shown in other countries such as China (6).

In addition to respiratory illness, air pollution has also been associated with increased risk for stroke and depression (7). Moreover, air pollution is related to cognitive decline and dementia $(8,9)$. Animal studies have demonstrated that the likely pathophysiology behind this phenomenon is ongoing neuroinflammation and neurodegeneration associated with hyperphosphorylated tau protein and amyloid plaques. In Sweden, traffic air pollution was related to both vascular dementia and Alzheimer's disease (10). The odds ratio for dementia was 1.07 for persons living within $50 \mathrm{~m}$ of a freeway as compared to 1.02 for those living within $200 \mathrm{~m}$ of a freeway (11). Indoor pollution is also detrimental and pollution from cooking with wood or coal indoors has been associated with impaired cognition (12).

\section{Stressors}

Numerous studies have shown that following natural disasters, e.g., earthquakes or hurricanes, there is an increase in hospitalizations and mortality in the following months. After the 2008 Sichuan (Wenchuan) earthquake in China, we had an opportunity to follow a group of 90-year-olds (13). In comparison to an age-matched group that we had followed in the prior years, there was a marked increase in mortality in this elderly population cohort for the year following the earthquake. Similarly, after Hurricane Maria in Puerto Rico, mortality rates increased specifically among the elderly population. This excess mortality occurred predominantly in persons 60 years and older and was due to cardiovascular disease, dementia, and sepsis (14).

In Hong Kong, adverse weather conditions were found to be Published online July 6, 2019, http://dx.doi.org/10.1007/s12603-019-1227-5 


\section{POPULATION HEALTH AND AGING}

associated with increased mortality in the oldest-old males from 1977-2008 (15). However, during this time, adverse political situations related to the return of Hong Kong to Chinese rule are also likely related to increased mortality demonstrated. There were increased mortality rates at the time the United Kingdom announced their decision to return Hong Kong to China and then again around the time of the actual return to Chinese rule in 1997. This strongly supports the concept that pure psychological stressors, whether related to weather conditions or political upheaval, etc., can increase mortality. Importantly, it should also be recognized that disaster evacuation among older persons is associated with increased mortality $(16,17)$. This suggests that disaster planning should prioritize "sheltering in place" for older persons whenever possible $(16,17)$.

Bereavement is another psychological stressor. There is a 2.50 increased odds ratio in the first month after the death of a spouse and this increased mortality likelihood is still present at 12-months after the spousal loss (18). The increase in mortality is predominantly due to increased deaths among men with cardiovascular disease (19). Following bereavement, women have been shown to spend an excess of $\$ 3,500$ on health expenses in the following 2 years (20) after spousal loss. In addition to increase in mortality, the loss of a spouse also is associated with functional impairment and increased morbidity (21).

\section{Green Spaces (Built Environment)}

The concept of "Green Space" is a central feature of the World Health Organization's Aging-Friendly Cities program. Green spaces have been found to improve interaction and socialization of the persons living in a geographical area. Loneliness is a major problem for many older persons and it is possible that for some people, the green spaces reduce loneliness (22). Other possible advantages of green spaces include ease of walking in a pleasant environment, improved ease of access to commercial destinations, increased public safety, a reduction in environmental pollution, and a decrease in neighborhood social stresses $(23,24)$. Walkable green spaces have been shown to decrease mortality of older persons regardless of function and socioeconomic status (25). Other advantages of green spaces include improved general health, improved quality of life, lower risk of heart disease, slower cognitive decline, reduced obesity, less lower body functional limitations and a better walking speed $(26,27)$ (Table 1).

\section{Climate Change}

Global warming is a major problem for older persons for several reasons (28). For instance, with the aging process, the body naturally loses some of its fine-tuned mechanisms needed to thermoregulate with temperature extremes. These include difficulty with sweating mechanisms needed for cooling and circulatory vasoconstriction mechanisms needed for warming.
Compounding on this, some medications reduce the ability of the body to thermoregulate. The implementation of population health-friendly policies requires that air-conditioned centers, e.g., shopping malls, churches, etc. are available for older persons to shelter in during in heat waves (29). It should be noted that extreme heat waves are also associated with an increase in ozone atmospheric pollution.

Table 1

Advantages of Green Spaces

Decreased obesity
Increased recreational activity
Reduced environmental pollution
Less stress
Improved health with less heart disease
Improved mental ability
Less decline in gait speed
Less loneliness
Less depression
Less decline in lower body function
Improved quality of life
Deceased mortality

\section{Nutrition}

Adequate nutrition plays a key role in maintaining function in older persons. In old age, weight loss is a major determinant of poor health outcomes (30). In older persons, a higher Body Mass Index (BMI), as long as there is adequate muscle mass, is protective against functional decline and mortality (31). Interestingly, protein energy malnutrition in older persons is independent of socioeconomic status and goes beyond the availability of resources to buy food (32). For this reason, screening for anorexia of aging, utilizing the Simplified Nutritional Appetite Questionnaire (SNAQ), is a key to early prevention of weight loss $(33,34)$. Anorexia, as determined by the SNAQ, is a determinant of quality of life in older persons (35).

Several studies have demonstrated that persons who adhere to a Mediterranean Diet have lower all-cause mortality and death from cardiovascular disease $(36,37)$. Mediterranean style diet is also related to improved physical performance (38) and a lower risk of dementia $(39,40)$. Extra virgin olive oil, one key component of the Mediterranean diet, appears to be particularly associated with a lower risk of dementia (41) and this is likely due to the phenyls in olive oil reducing oxidative damage in the brain (42). Fruit and vegetable consumption independently reduce frailty (43), disability (44) and mortality (45). Similarly, a high ingestion of fish may improve outcomes (46), whereas increased red meat ingestion leads to increased mortality (47). 


\section{THE JOURNAL OF NUTRITION, HEALTH \& AGING@}

These data support dietary diversity as a reasonable approach to diet in older persons $(48,49)$. From the population health point of view, it is important to make certain that fruit and vegetables are readily available at a reasonable cost in low socio-economic inner-city areas (50). The role in developing community gardens is important in this regard (51) and may lead to overall better nutrition and reduced morbidity and mortality.

\section{Secondary Prevention: Screening for Geriatric Syndromes}

An important component of aging friendly health systems is to provide screening for geriatric syndromes (52). Early detection for frailty (53), sarcopenia (54), anorexia of aging (55), falls $(56,57)$ and cognitive dysfunction (58) is a key component to improve outcomes for older persons, as targeted individualized interventions may be put in place. These interventions are often modest, but have great impacts on health outcomes. For example, a simple algorithm has been developed to identify causes and interventions for those who screen positive for frailty utilizing the FRAIL screen (59). In Australia, it has been recommended by the Australian government that all persons over 65 years of age be assessed for frailty by their family practitioner through utilizing the FRAIL screen (60). In fact, the Minister of Aged Care in Australia considers a positive screen on the FRAIL screen to be "the canary in the coal mine" for older persons in that frailty is indicative of poor health outcomes and disability and thus must be treated. From the population health viewpoint, group exercise programs for persons with sarcopenia (61) and frailty, and cognitive stimulation group therapy for those with moderate dementia $(62,63)$ should be available for all members of the population.

\section{Conclusion}

The need to develop population health programs targeted specifically at older persons is long overdue. As shown in Figure 1, the factors leading to longevity around the world do not always correlate with common recommendations. An example of this is the recommendation for very low salt. Population health data supports moderate, but not very low, salt intake $(64,65)$. Similarly, as pointed out in a recent editorial in our Journal, there is no evidence to support very high vitamin D supplementation and limited data to support vitamin D intake in many older persons (66). Furthermore, supplementation with antioxidant vitamins has been shown to actually increase mortality $(67,68)$. This highlights the sentiment that much caution needs to be taken in interpreting available data to any specific population at a population level. What may be useful and improve health outcomes in younger individuals, may not have the same positive effects in the elderly and vice versa. In conclusion, health care is transitioning to precision-driven, patient-centered medicine utilizing artificial intelligence and the same approaches need to be used for population health (69).
Figure 1

Examples of Factors Affecting Population Health from Around the World

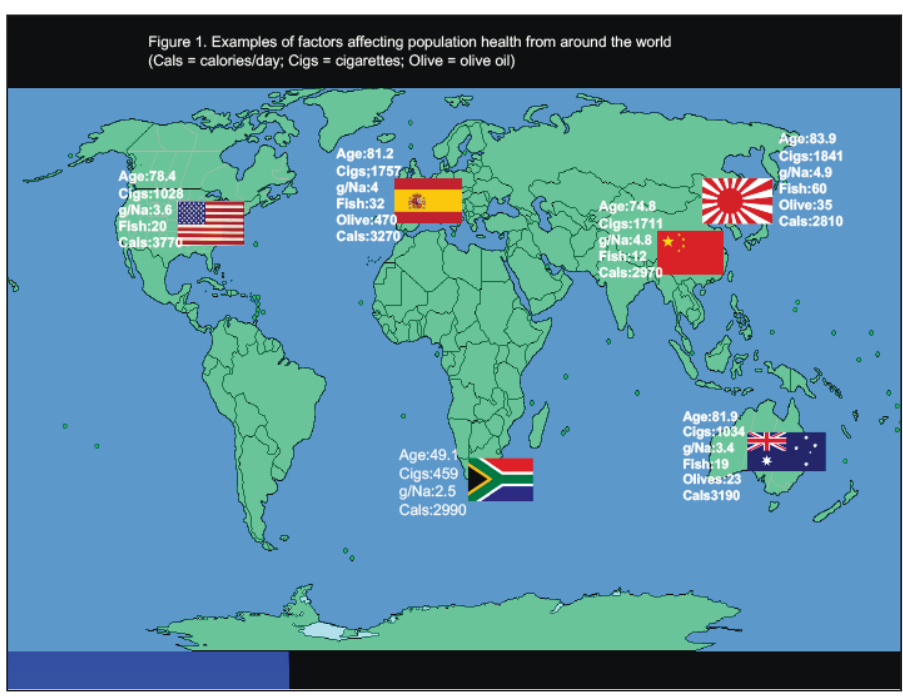

$(\mathrm{CALS}=$ calories $/$ day $;$ Cigs $=$ cigarettes $;$ Olive $=$ olive oil

Disclosures: The authors declare there are no conflicts.

\section{References}

1. Kindig D, Stoddard G. What is population health? Am J Publ Health 2003;93:380383.

2. McKeown T. The Place of Medicine: Dream, Mirage or Nemesis. England: Nuffield Provincial Hospitals Trust. 1970.

3. Anonymous. "The Great Smog of 52" metoffice.gov.uk. Retrieved 7 June 2019.

4. Pope CA, Ezati M, Dockerg DN. Fine particle air pollution and life expectancy in the United States. N Engl J Med 2009;360:376-386.

5. Anonymous. wwwl.nye.gov 2019.

6. Zhu G, Hu W, Liu Y, et al. Health burdens of ambient PM2.5 pollution across Chinese cities during 2006-2015.

7. Calderon-Garciduenas L, Calderon-Garciduenas A, Torres-Jardon R, et al. Air pollution and your brain: What do you need to know right now. Prim Health Care Res Dev 2015;16:329-345.

8. Peters R, Ee N, Peters J, et al. Air pollution and dementia: A systematic review. J Alzheimers Dis 2019; Feb 11. DOI: 10.3233/JAD-180631. [Epub ahead of print].

9. Power MC, Adar SD, Yanosky JD, Weuve J. Exposure to air pollution as a potential contributor to cognitive function, cognitive decline, brain imaging, and dementia: A systematic review of epidemiologic research. Neurotoxicology 2016;56:235-253.

10. Oudin A, Forsberg B, Adolfsson AN, et al. Traffic-related air pollution and dementia incidence in Northern Sweden: A longitudinal study. Environ Health Perspect 2016;124:306-312.

11. Chen H, Kwong JC, Copes R. Living near major roads and the incidence of dementia, Parkinson's disease, and multiple sclerosis: A population-based cohort study. Lancet 2017;389:718-726.

12. Saenz JL, Wong R, Ailshire JA. Indoor air pollution and cognitive function among older Mexican adults. J Epidemiol Community Health 2018;72:21-26.

13. Flaherty JH, Dong B, Wu H, et al. Observational study of 1-year mortality rates before and after a major earthquake among Chinese nonagenarians. J Gerontol A Bio Sci Med Sci 2011;66:355-361

14. Cruz-Cano R, Mead El. Causes of excess deaths in Puerto Rico after Hurricane Maria: A time-series estimation. AJPH 2019; doi: 10.2105/AJPH.2019.305015. [Epub ahead of print].

15. Chau PH, Yen E, Morley JE, Woo J. The effects of environmental stressors on the mortality of the oldest old male population in Hong Kong, 1977-2006.

16. Prior A, Fenger-Gron M, Davydow DS, et al. Bereavement, multimorbidity and mortality: A population-based study using bereavement as an indicator of mental stress. Psychol Med 2018;48:1437-1443.

17. Willoughby M, Kipsaina C, Ferrah N, et al. Mortality in nursing homes following emergency evacuation: A systematic review. J Am Med Dir Assoc 2017;18:664-670.

18. Nomura S, Blangiardo M, Tsubokura M, et al. Post-nuclear disaster evacuation and 


\section{POPULATION HEALTH AND AGING}

survival amongst elderly people in Fukushima: A comparative analysis between evacuees and non-evacuees. Prev Med 2016;82:77-82.

19. Stahl ST, Arnold AM, Chen JY, Anderson S, Schulz R. Mortality after bereavement: The role of cardiovascular disease and depression. Psychosom Med 2016;78:697-703.

20. Ornstein KA, Garrido MM, Siu AL, et al. An examination of downstream effects of bereavement on healthcare utilization for surviving spouses in a national sample of older adults. Pharmacoeconomics 2019;37:585-596.

21. Hajek A, Luck T, Brettschneider C, et al. Factors affecting functional impairment among elderly Germans - results of a longitudinal study. J Nutr Health Aging 2017;21:299-306

22. van den Berg MM, van Poppel M, van Kamp I, et al. Do physical activity, social cohesion, and loneliness mediate the association between time spent visiting green space and mental health? Environ Behav 2019;51:144-166

23. Moran M, Van Cauwenberg J, Hercky-Linnewiel R, et al. Understanding the relationship between the physical environment and physical activity in older adults: A systematic review of qualitative studies. Int J Behav Nutr Phys Act 2014;11:79.

24. Ailshire J, Karraker A, Clarke P. Neighborhood social stressors, fine particulate matter air pollution, and cognitive function among older U.S. adults. Soc Sci Med 2017; $172: 56-63$.

25. Takano T, Nakamura K, Watanabe M. Urban residential environments and senior citizens' longevity in megacity areas: The importance of walkable green spaces. J Epidmiol Community Health 2002;56:913-918.

26. Schootman M, Andresen EM, Wolinsky FD, et al. Neighborhood conditions and risk of incident lower-body functional limitations among middle-aged African Americans. Am J Epidemiol 2006;163:450-458.

27. Barnett DW, Barnett A, Nathan A, et al; Council on Environment and Physica Activity (CEPA) - Older Adults working group. Built environmental correlates of older adults' total physical activity and walking: A systematic review and metaanalysis. Int J Behav Nutr Phys Act 2017;14:103.

28. Bunker A, Wildenhain J, Vandenbergh A, et al. Effects of air temperature on climatesensitive mortality and morbidity outcomes in the elderly: A systematic review and meta-analysis of epidemiological evidence. EBioMedicine 2016;6:358-368.

29. Diaz J, Garcia R, Velazquez de Castro F, et al. Effects of extremely hot days on people older than 65 years in Sville (Spain) from 1986 to 1997. Int J Biometeorol 2002;46:145-149.

30. Morley JE. Editorial: Defining undernutrition (malnutrition in older persons. J Nutr Health Aging 2018;22:308-310.

31. Morley JE. Editorial: Screening for malnutrition (undernutrition) in primary care. J Nutr Health Aging 2019;23:1-3.

32. Hoogendijk EO, Flores Ruano T, Martinez-Reig M, et al. Socioeconomic position and malnutrition among older adults: Results from the FRADEA study. J Nutr Health aging 2018;22:1086-1091.

33. Morley JE. Anorexia of aging: A true geriatric syndrome. J Nutr Health Aging 2012; 16:422-425.

34. Warne C, Forrester IT, Jones L, Morley JE. Editorial: Screening for the anorexia of aging. J Nutr Health Aging 2019;23:398-400.

35. Acar Tek N, Karacil-Ermumcu MS. Determinants of health related quality of life in home dwelling elderly population: Appetite and nutritional status. J Nutr Health Aging 2018;22:996-1002.

36. Limongi F, Noale M, Gesmundo A, et al. Adherence to the Mediterranean diet and all-cause mortality risk in an elderly Italian population: Data from the ILSA study. J Nutr Health Aging 2017;21:505-513.

37. Salas-Salvado J, Becerra-Tomas N, Garcia-Gavilan JF, et al. Mediterranean diet and cardiovascular disease prevention: What do we know? Prog Cardiovasc Dis 2018;61:62-67.

38. Fougere B, Mazzuco S, Spagnolo P, et al. Association between the Mediterraneanstyle dietary pattern score and physical performance: Results from TRELONG study. J Nutr Health Aging 2016;20:415-419.

39. Martinez-Lapiscina EH, Clavero P, Toledo E, et al. Mediterranean diet improves cognition: the PREDIMED-NAVARRA randomized trial. J Neurol Neurosurg Psychiatry 2013;84:1318-1325.

40. Berendsen AM, Kang JH, Feskens EJM, de Groot CPGM, et al. Association of longterm adherence to the MIND diet with cognitive function and cognitive decline in American Women. J Nutr Health Aging 2018;22:222-229.

41. Martinez-Lapiscina EH, Clavero P, Toledo E, et al. Virgin olive oil supplementation and long-term cognition: The PREDIMED-NAVARRA randomized, trial. J Nutr Health Aging 2013;17:544-552.

42. Farr SA, Price TO, Dominguez LJ, et al. Extra virgin olive oil improves learning and memory in SAMP8 mice. J Alzheimers Dis 2012;28:81-92.

43. Kojima G, Avgerinou C, Ililffe S, et al. Fruit and vegetable consumption and frailty: A systematic review. J Nutr Health Aging 2018;22:1010-1017.
44. Ribeiro SM, Morley JE, Malmstrom TK, Miller DK. Fruit and vegetable intake and physical activity as predictors of disability risk factors in African-American middleaged individuals. J Nutr Health Aging 2016;20:891-896.

45. Aune D, Giovannucci E, Boffetta P, et al. Fruit and vegetable intake and the risk of cardiovascular disease, total cancer and all-cause mortality - a systematic review and dose-response meta-analysis of prospective studies. Int J Epidemiol 2017;46:10291056.

46. Kromhout D, Bosschieter EB, de Lezenne Coulander C. The inverse relation between fish consumption and 20-year mortality from coronary heart disease. N Engl J Med 1985;312:1205-1209.

47. Zheng Y, Li Y, Satija A, et al. Association of changes in red meat consumption with total and cause specific mortality among US women and men: Two prospective cohort studies. BMJ 2019;365:12110. Doi: 10.1136/bmj.12110.

48. Yin Z, Fei Z, Qiu C, et al. Dietary diversity and cognitive function among elderly people: A population-based study. J Nutr Health Aging 2017;21:1089-1094.

49. Osuka Y, Kojima N, Yoshida Y, et al. Exercise and/or dietary varieties and incidence of frailty in community-dwelling older women: A 2-year cohort study. J Nutr Health Aging 2019;23:425-430.

50. Martin KS, Ghosh D, Page M, et al. What role do local grocery stores play in urban food environments? A case study of Hartford-Connecticut. PLoS One 2014;9:e94033.

51. Alaimo K, Beavers AW, Crawford C, et al. Amplifying health through community gardens: A framework for advancing multicomponent, behaviorally based neighborhood interventions. Curr Environ Health Rep 2016;3:302-312.

52. Sanford AM, Berg-Weger M, Lundy J, Morley JE. Editorial: Aging friendly health systems. J Nutr Health Aging 2019;23:119-121.

53. Morley JE, Malmstrom TK, Miller DK. A simple frailty questionnaire (FRAIL) predicts outcomes in middle aged African Americans. J Nutr Health Aging 2012;16:601-608.

54. Dent E, Morley JE, Cruz-Jentoft AJ, et al. International clinical practice guidelines for sarcopenia (ICFSR): Screening, diagnosis and management. J Nutr Health Aging 2018;22:1148-1161.

55. Jadczak AD, Visvanathan R. Anorexia of aging - an updated short review. J Nutr Health Aging 2019;23:306-309.

56. Morley JE. F3ALLS Approach to preventing falls. J Nutr Health Aging 2018;22:748 750.

57. Rouck JE, Malmstrom TK, Morley JE. Initial validation of the Toulouse St. Louis University Mini Falls Assessment in older adults. J Nutr Health Aging 2018;22:880 884.

58. Malmstrom TK, Voss VB, Cruz-Oliver DM, et al. The rapid cognitive screen (RCS): A point-of-care screening for dementia and mild cognitive impairment. J Nutr Health Aging 2015;19;741-744.

59. Morley JE. Rapid geriatric assessment: Secondary prevention to stop age-associated disability. Clin Geriatr Med 2017;33:431-440.

60. www.agedcareguide.com.au/talking-aged-care/frailty-detection-a-game-changer-forolder-australians

61. Izquierdo M, Rodriguez-Manas L, Caas-Herrero A, et al. Is it ethical not to prescribe physical activity for the elderly frail? J Am Med Dir Assoc 2016;17:779-781.

62. Morley JE, Cruz-Oliver DM. Cognitive stimulation therapy. J Am Med Dir Assoc 2014;15:689-691.

63. Morley JE, Berg-Weger M, Lundy J. Editorial: Nonpharmacological treatment of cognitive impairment. J Nutr Health Aging 2018;22:632-633.

64. O'Donnell M, Mente A, Rangarajan S, et al. Urinary sodium and potassium excretion, mortality, and cardiovascular events. N Engl J Med 2014;371:612-623.

65. Stolarz-Skrzypek K, Kuznetsova T, Thijs L, et al. Fatal and nonfatal outcomes, incidence of hypertension and blood pressure changes in relation to urinary sodium excretion. JAMA 2011;305:1777-1785.

66. Morley JE. Editorial: Vitamin D: Does the Emperor have no clothes? J Nutr Health Aging 2019;23:316-317.

67. Bjelakovic G, Nikolova D, Gluud LL, et al. Antioxidant supplements for prevention of mortality in healthy participants and patients with various diseases. Cochrane Database Syst Rev 2012;14:CD007176.

68. Bjelakovic G, Nikoliva D, Gluud C. Meta-regression analyses, meta-analyses, and trial sequential analyses of the effects of supplementation with beta-carotene, vitamin A, and vitamin E singly or in different combinations on all-cause mortality: Do we have evidence for lack of harm? PLoS One 2013;8(9):e74558.

69. Morley JE, Anker SD. Myopenia and precision (P4) medicine. J Cachexia Sarcopenia Muscle 2017;8:857-863. 